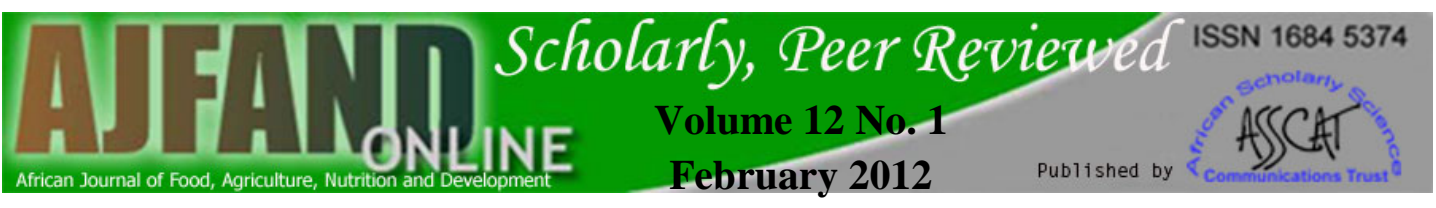

\title{
STREET FOODS CONTRIBUTE TO NUTRIENT INTAKES AMONG CHILDREN FROM RURAL COMMUNITIES IN WINNEBA AND TECHIMAN MUNICIPALITIES, GHANA
}

\author{
Micah EB ${ }^{1}$, Colecraft EK* ${ }^{1}$, Lartey $\mathbf{A}^{1}$, Aryeetey $\mathbf{R}^{2}$ and GS Marquis ${ }^{3}$
}

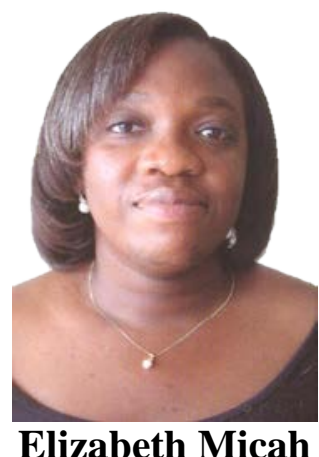

*Corresponding author email: ecolecraft@ug.edu.gh

${ }^{1}$ Department of Nutrition and Food Science, University of Ghana, Legon, Ghana

${ }^{2}$ School of Public Health, University of Ghana, Legon, Ghana

${ }^{3}$ School of Dietetics and Human Nutrition, CINE Bldg., Macdonald Campus, McGill University, 21, 111 Lakeshore Rd., Ste. Anne-de-Bellevue, Quebec, Canada H9X 3V9 


\section{ABSTRACT}

The contribution of Street Foods (SF) to the energy and nutrient intakes of young children in rural African communities has been understudied. Under the Enhancing Child Nutrition through Animal Source Food Management (ENAM) project, a microcredit and nutrition education intervention with caregivers of children 2-to 5years old in rural Ghana, the prevalence of SF consumption by young children and the contribution SF make to children's energy, nutrient and Animal Source Food (ASF) intakes were assessed. A simple random sample of 172 caregiver-child pairs residing in the ENAM intervention communities in Winneba and Techiman municipalities participated in this study. A semi-structured questionnaire was used to interview caregivers about SF purchased for their 2- to 5-years old children in the previous week. During two non-consecutive 12-hour home observations, all foods consumed by a subsample of the children $(n=45)$ were weighed. Energy and nutrient content of weighed foods were estimated using the Ghanaian food composition table. About $80 \%$ of caregivers purchased SF for their child at least once that previous week. Most (76\%) SF purchased were grain-based and were purchased as complete meals. The children's total ASF intake was $69.9 \pm 11.0$ g; quantity of ASF consumed was similar but their sources of ASF differed between the two municipalities. In Techiman, SF contributed $36 \%$ of the ASF consumed over the two observation days compared to $4.2 \%$ in Winneba $(\mathrm{P}=0.003)$. Overall, $\mathrm{SF}$ contributed $35 \%$ of energy, $43 \%$ of vitamin A, $20 \%$ of vitamin $\mathrm{B}_{12}, 30 \%$ of zinc, $34 \%$ of iron, and $54 \%$ of calcium consumed by children. The contribution of SF to young children's dietary intakes, especially their ASF intakes and hence micronutrient intakes, may improve overall dietary quality. This study provides evidence that, SF is an important part of children's diets in rural Ghana and could be an important target for food-based interventions to enhance nutrition in young children.

Key words: Street foods, Children, Rural Ghana 


\section{INTRODUCTION}

Street Foods (SF) are prepared and sold by vendors and hawkers in streets and other public places [1]. According to the United Nations Food and Agriculture Organization, 2.5 million people worldwide consume SF every day [2]. Urban dwellers in sub-Saharan Africa and Asiaspend 15 to $50 \%$ of their household food budgets on $\mathrm{SF}[3,4]$ with the highest percentages among the smallest and poorest families [5, 6]. Urban residents in Accra, the capital city of Ghana, spend more than $33 \%$ of their food budget on SF [3].

A significant part of SF consumers are the school-aged children who spend a large proportion of their day away from home [7, 8]. A study in Senegal reported that almost one third of all street food consumers were either children or adolescents [8]. A study conducted in Mali also found that children were important consumers of SF and that they had considerable independence in choosing which SF to consume [9]. In one study, researchers interviewed 421 Tunisian school children (mean age of 10 years) about street food purchases [10]. The children reported that they used more than $75 \%$ of their pocket money to buy SF, with the largest proportion of the money spent on sandwiches.

Research studies on the influence of SF on children's diets have yielded mixed results. Street foods may benefit food consumption patterns, contributing an affordable source of food especially for the urban poor; thus, SF could be considered a dietary coping strategy to reduce food insecurity $[2,11]$. This was the case among a sample of Haitian school children who consumed an estimated 400 kcal per day from street foods [12]. SF could also contribute important nutrients to children's intakes. A 1992 household food consumption survey that was part of the Bogor Street food project in Indonesia found that street foods contributed to the diets of even younger children [13]. The proportion of total nutrient intake from street foods was highest among pre-school aged children. On average, 30\% of energy, 26\% of protein, and $44 \%$ of iron intake originated from street foods. In contrast, as little as (5\%) of vitamin A intake was obtained from SF. Even infants consumed substantial quantities of street foods.

Other studies, however, have reported negative nutritional outcomes in school aged children, including greater total energy intakes and poorer diet qualities with the increased consumption of street foods[2,14]. Street foods could also be a health risk if prepared in unsanitary conditions or vendors use unhygienic food handling techniques. For example in Ghana, a study conducted by Mensah [15] showed that out of 511 food items that were examined, nearly $70 \%$ were contaminated with mesophilic bacteria, about 23\% contained staphylococcus aureus and approximately $34 \%$ contained enterobacteriaceae. Although microbial loads of most of the foods studied were within acceptable levels, samples of salads, macaroni, fufu (boiled tubers pounded into stiff dough), omo-tuo (riceballs) and red pepper sauce had unacceptable levels of contamination. The final preparations of these foods do not involve a heating process and thus may have been susceptible to contamination as a result of poor handling techniques. 
The consumption of SF may present an advantage, however, if consumers are educated to make safe and nutritious food choices. Good nutritious food choices could include foods based on animal products. Animal Source Foods (ASF) as a component of meals have been found to improve quality of young children's diet and subsequently improve nutritional status and cognitive performance in Kenya. [16-18]. These benefits are attributed to the high bio-availability of micronutrients including zinc, iron, vitamin $A$, calcium and vitamin $\mathrm{B}_{12}$ [19]. The contribution of ready-to-eat animal source street foods to the quality (energy, nutrient intakes, and dietary diversity) of the diet of young children remains unknown. In the current study, we documented street food consumption and estimated the contribution of street food to nutrient intakes and ASF consumption of children 2-to 5- years old in four Ghanaian rural communities.

\section{MATERIALS AND METHODS}

This was a cross-sectional study undertaken in two rural communities in the Coastal Savannah (Winneba municipality) and two rural communities in the Forest-Savannah Transitional (Techiman municipality) ecological zones of Ghana. The rural communities were part of the Enhancing Nutrition through Animal Source Food Management (ENAM) project that implemented a microcredit and educational intervention with caregivers of 2- to 5-years old children to improve access to ASF and its use in children's diets. The ENAM project census of caregivers of 2- to 5years old children was used to randomly select 172 caregiver-child pairs from these four communities, regardless of their involvement in the ENAM project.

Trained local field assistants used a semi-structured questionnaire to collect data on socioeconomic and demographic characteristics of caregivers either at their home or workplace. Using local criteria developed by community opinion leaders, household wealth was categorized as low, medium or high. A food frequency questionnaire was used to record foods, including SF and ASF that were consumed by children in the previous week. The place and time of day the food was consumed was recorded. For each SF consumed, caregivers were asked to indicate whether the food was purchased as a snack (Purchased food items consumed by children in-between meals to sustain the child till the next major meal), complete meal (food purchased for the child's consumption as a main meal without adding to it or further processing it), or part of a meal (Food purchased for the child's consumption as part of a main meal which is added to an accompaniment that was not purchased). Caregivers who had purchased SF were asked for reasons why they had purchased the SF.

Two non-consecutive unannounced 12-hour weighed food observations were completed by field staff on a randomly selected subsample of 45 children who had consumed purchased SF in the previous week. The targeted sample was 49 , however, the data from four children were incomplete and were excluded, leaving data from 45 children for the analysis. The two selected times captured dietary intakes of the children on market and non-market days in the Techiman municipality and on fishing and non-fishing days in the Winneba municipality. During the observations, all foods

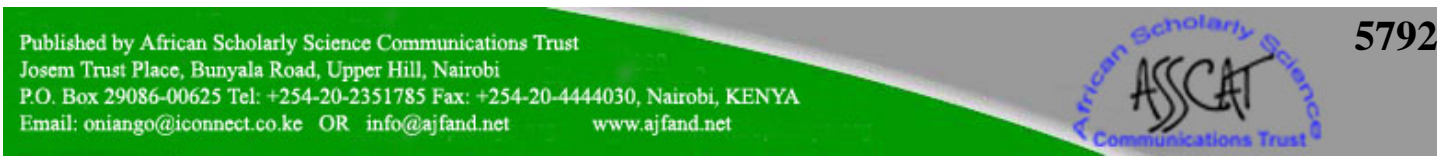


and beverages, except for water, consumed by the children were weighed using a Compact electronic food weighing scale (Camry Electronic Co. Ltd, Guangdong, China) and the weights were recorded to the nearest $0.1 \mathrm{~g}$. To estimate food intake for the whole day (24 hours), caregivers were interviewed about foods consumed outside the 12-hour weighed food observation period. Caregivers were provided with common household measures to estimate food and beverage consumption.

Data were coded and entered into Microsoft Access and subsequently analyzed using SPSS (Version 13.0). Ghanaian food composition tables [20] were used to estimate energy, protein, vitamin $A$, zinc, iron, vitamin $B_{12}$, and calcium content of the foods consumed. The detailed food intake assessment on the subsample of 45 children was used for this analysis. The percent contribution of SF to the total energy and individual nutrients were computed. All data are presented as mean \pm standard error (SE) and significance was recorded at $\mathrm{p}<0.05$ unless indicated otherwise.

The study was approved by the Institutional Review Board at the Noguchi Memorial Institute for Medical Research, University of Ghana. Written informed consent was obtained from all caregivers who agreed to participate.

\section{RESULTS}

\section{Characteristics of caregiver-child pairs}

Most (77\%) of the caregivers interviewed were the biological mothers of the 2-to5year old children. The mean age of the caregivers was 35.0 \pm 1.2 years (Table 1). Caregivers from the Winneba communities were about 6 years older $(p=0.010)$ and had higher parity than the caregivers from the Techiman communities $(p=0.002)$. Trading and farming were the main occupations of the caregivers. The Winneba and Techiman area caregivers did not differ with respect to years of schooling completed, marital status, household wealth, and household size. Compared to Techiman caregivers, more than twice as many Winneba area caregivers lived in female-headed households (Table $1 ; \mathrm{p}<0.01)$; fewer $(50.0 \%$ vs.66.7\%; $\mathrm{p}=0.06)$ lived in extended family arrangements. Techiman children were 6 months older than children from the Winneba communities (Table $1 ; \mathrm{p}=0.03$ ).

\section{Prevalence and types of SF consumed by 2-to5-years old children}

About $80 \%$ of caregivers in the two study areas had purchased SF for their children at least once in the previous seven days.Grain-based porridges made from rice, millet, maize, or wheat were the most commonly purchased SF(Figure 1). Rice dishes besides porridge were also popular SF purchased for children in the Techiman communities. Nearly $40 \%$ of the Techiman area children had consumed a rice-based SF compared to only $16 \%$ of children from the Winneba communities $(p=0.01)$. Other SF purchased for children included stiff porridges (made from fermented or unfermented corn dough or millet meal) such as banku, akple, tuo zaafi, and kenkey, typically consumed with a sauce or thick soup such as groundnut or palm soup. Foods prepared from roots and tubers such as cassava andyam as well as plantains were frequently consumed (75.7\%) as meals and sometimes as fried snacks(7.8\%). Flourbased snacks such as doughnuts and tarts as well as fruits were also consumed.

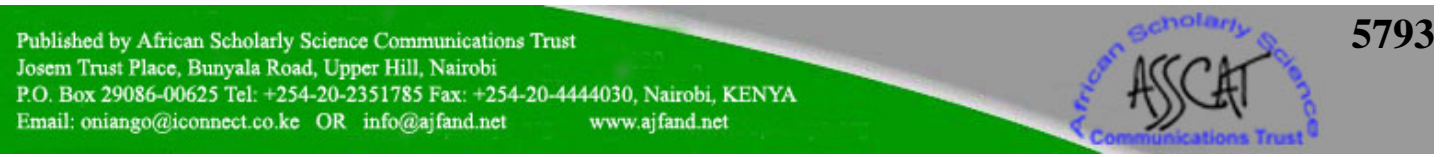



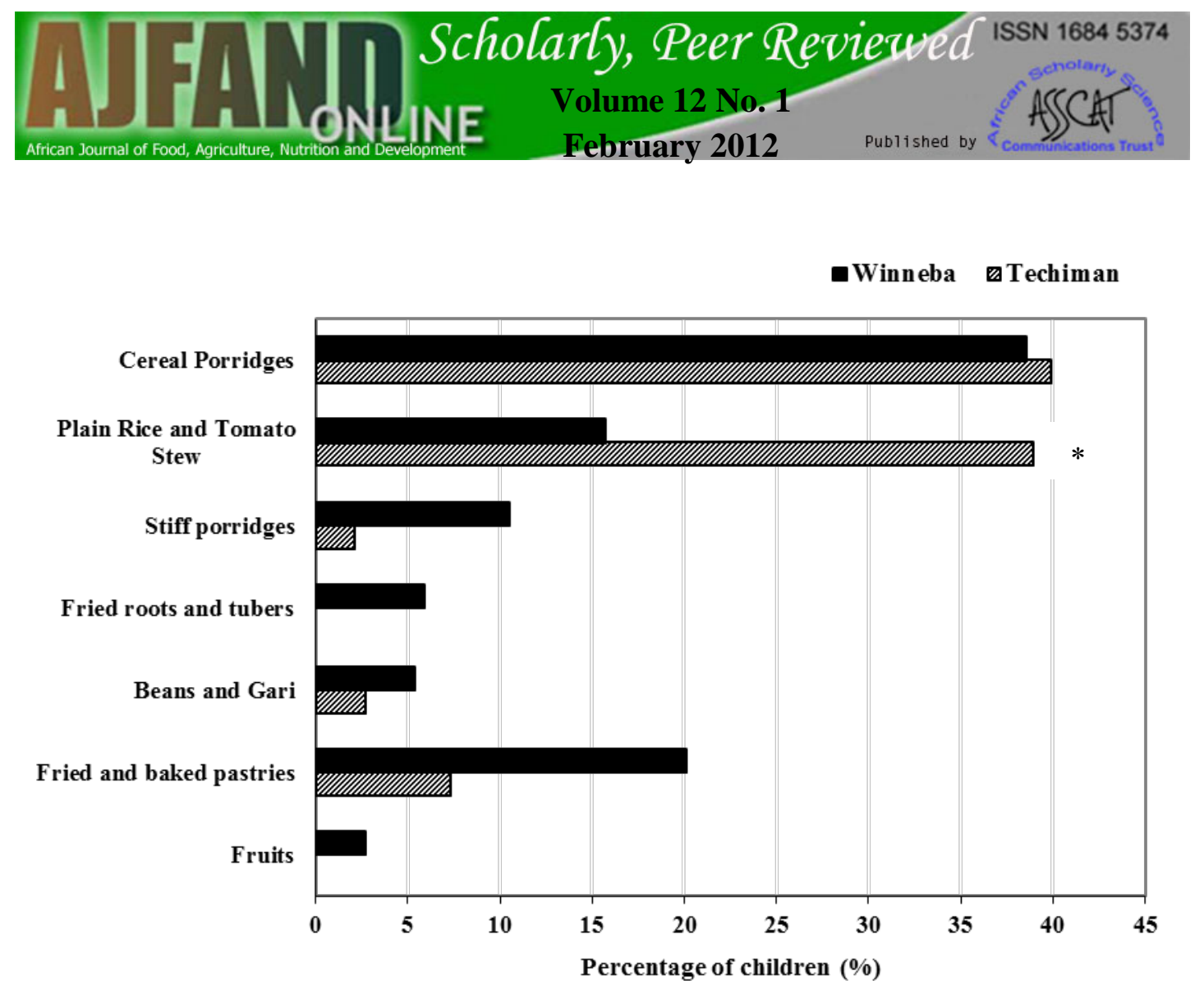

Figure 1: Street food consumed by 2-to 5-years old children in the Winneba and Techiman study communities; *Significant differences at between groups; $p<0.05$ )

The majority of SF (75.7\%) was consumed by children as complete meals. Most of the caregivers purchased SF for their children in the morning (75\%); it was less common to purchase SF in the afternoon (10.2\%) and evening (3.0\%). Buying behaviour, however, differed by region; Techiman caregivers purchased SF more in the morning, whereas Winneba caregivers purchased SF more in the afternoon $(\mathrm{p}<0.001)$. 


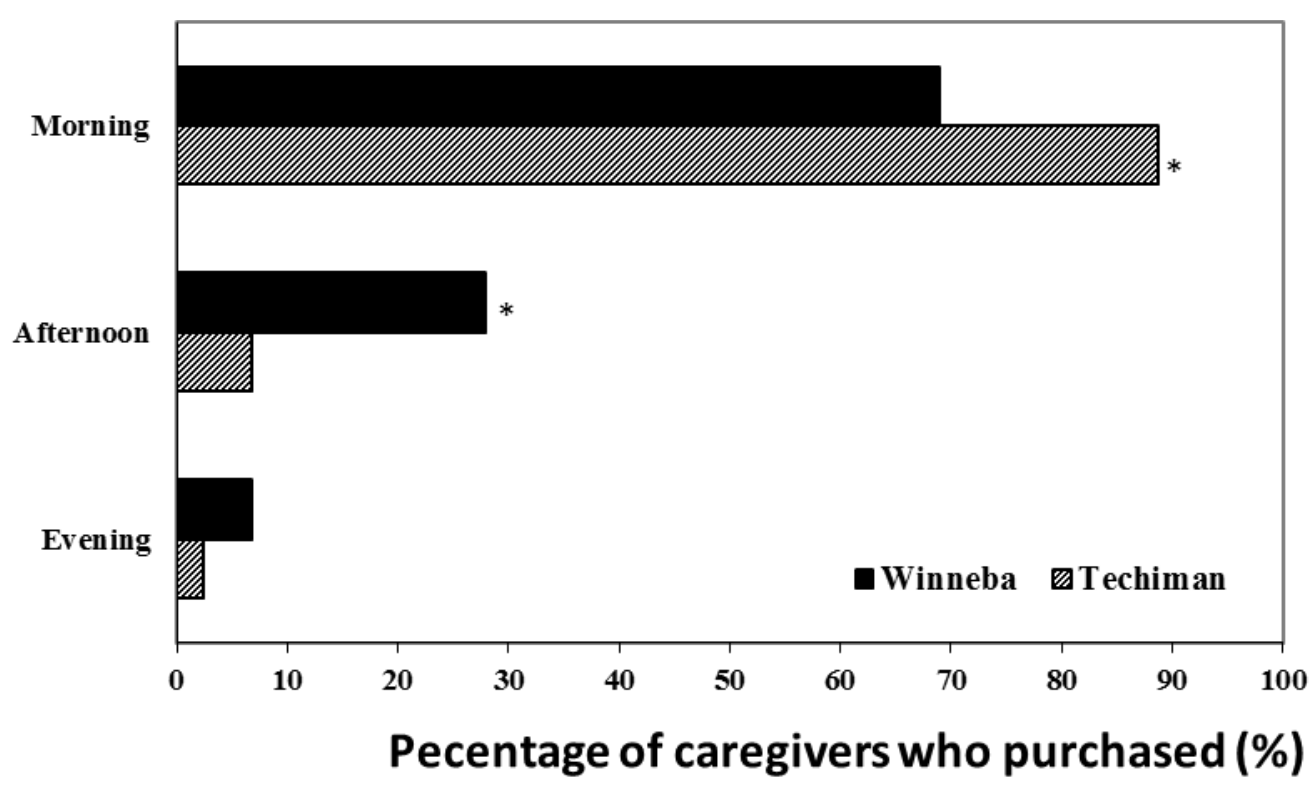

Figure 2: Time of day that Street Foodwere purchased for 2-to 5-years old children in the Winneba and Techiman municipalities. *Significant differences between the two ecological zones; $<<0.05$.

\section{Contribution of SF to ASF intakes}

The children consumed $69.9 \pm 11.0 \mathrm{~g}$ of ASF on the observation days (Table 2). SF contributed $35.7 \%$ of the ASF consumed by children in the Techiman communities and $4.2 \%$ in the Winneba area $(\mathrm{P}<0.01)$. Almost $50 \%$ of the plain rice and tomato stew meals consumed contained some ASF however, only $26 \%$ of the banku, akple, kenkey with soup or stew contained ASF. Cereal porridges (maize, millet, wheat and rice) as well as waakye (rice boiled together with beans) and jollof rice (rice boiled with tomato sauce) also contained ASF although these foods contributed less than $10 \%$ of total ASF intake. In the mornings, caregivers in Techiman were more likely to include ASF in children's diets $(\mathrm{p}=0.001)$ than caregivers in Winneba. However, the opposite trend was observed in the afternoons ( $\mathrm{p}=0.021$ ).

The types of ASF found in SF purchased for the children were fish powder (mainly used as a condiment), fish, beef, egg, milk, and poultry. Overall, ASF from SF contributed $10.3 \pm 3.0 \%$ to energy, $12.0 \pm 3.7 \%$ to protein, $13.1 \pm 4.7 \%$ to vitamin A, $9.3 \pm 3.1 \%$ to calcium, $18.3 \pm 8.0 \%$ to iron, $10.7 \pm 3.1 \%$ to zinc, and $11.6 \pm 5.4 \%$ to vitamin $\mathrm{B}_{12}$ intakes (Table 3).The ASF from SF contributed significantly more energy, calcium, iron and zinc $(\mathrm{p}<0.05)$ but not protein to the intakes of the children in the Techiman study areas as compared to the children in the Winneba communities. 


\section{Contribution of purchased SF to total energy and nutrient intakes}

In both sites, SF provided about 35.5\% of children's total energy intakes (Table 4). Street foods also contributed at least $20 \%$ of protein, vitamin $\mathrm{B}_{12}$, zinc and iron, over $40 \%$ of vitamin A, and over $50 \%$ of calcium. Study areas only differed in SF contribution to vitamin $\mathrm{B}_{12}$ which was higher in Techiman compared to Winneba $(\mathrm{P}=0.03)$.

\section{Reasons for caregivers' purchase of SF for 2-to 5-years old children}

Caregivers identified time constraints as a major reason for feeding their children SF. This reason was reported more frequently in Techiman (67\%) than in Winneba (40\%). Other reasons included convenience (54.1\%), child preference for a particular SF (30.8\%), lack of money for purchasing food ingredients to prepare a meal (15.7\%), and purchase of SF as a snack or school meal for the child (24.4\%).

\section{DISCUSSION}

The findings indicate that SF constituted a significant part of young children's meals in rural communities from the Techiman and Winneba municipalities, which is similar to reports from urban communities [6, 13, 18, 21]. In a study in a suburb of Accra, the capital city of Ghana, Mensah et al. [15] found that about $60 \%$ of mothers supplemented their children's diet with SF. Colecraft et al. [22] assessed the diets of young children attending nutrition rehabilitation centers in Accra and found that purchased foods in the children's diets increased $(\mathrm{p}<0.001)$ progressively from admission $(24.1 \pm 2.7 \%)$ to recovery $(48.6 \pm 4.1 \%)$. It is clear from the study that the consumption of SF by young children is not only an urban phenomenon but it also exists in the rural areas. This significant change in the food consumption patterns of rural households in Ghana, especially among young children is rather surprising. Informal discussions with caregivers at the end of the study were conducted to come to an understanding of this feeding behavior. Mothers reported that the increased economic pressure of daily life has caused many who were previously housewives to engage in economic activities to help raise income for the maintenance of the household, even in rural settings. This has resulted in women spending less time in the home and has necessitated dependence on SF to supplement household diets, even for young children. Secondly, most of these rural communities were agrarian and grew their own food. Thus, in the lean season when food ingredients were relatively unavailable, SF was a cheaper alternative to cooking home meals. Some mothers reported that children developed a preference for SF, even when home-made foods were available. Mothers also reported that they usually gave their school-aged children money to buy meals or snacks at school. The growing body of evidence demonstrating the significant contribution that street foods make to young children's diets provides ample justification for interventions to improve the nutrient quality of street foods that target children.

The present study also revealed that although SF contributed similarly to energy, zinc and vitamin $A$ intakes across the study areas, they contributed more vitamin $B_{12}$ to the

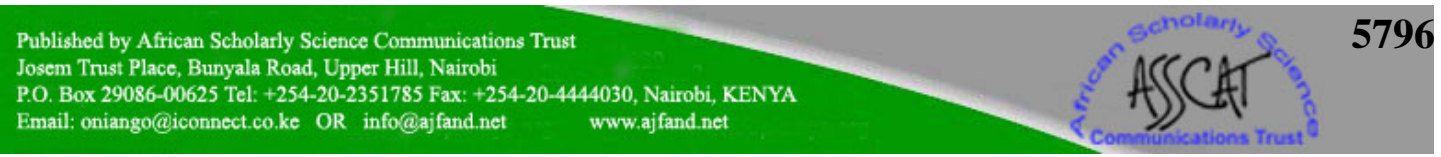


diets of Techiman municipality children compared to those in Winneba municipality. The contribution of more Vitamin $\mathrm{B}_{12}$ to the diets of the Techiman municipality children may be a reflection of the higher consumption of ASF from SF in Techiman as compared to Winneba communities.

Other studies also found that street foods contribute to energy, protein, iron, and vitamin A [12]. Thus SF may be advantageous for young children if good choices of food items, such as ASF, are considered when purchasing them. The majority of SF were consumed by the young children as full meals and reflected the typical diets that were likely to be prepared at home. Most of the SF was purchased in the morning and this was when caregivers were likely to purchase SF with ASF. One level of intervention therefore, should be to build caregivers' capacity to make good food choices when purchasing SF for their young children.

Time constraints were the most important reason caregivers gave for feeding their young children SF. The Equity Policy Center has reported that the time saved in preparation of meals by women is a factor that makes SF cost effective in developing countries [1]. The report also indicated that many traditional foods involve lengthy preparation and the purchase of street foods allows women to substitute time spent in food preparation for income-generation activities.

In summary, the growing evidence of high patronage of street foods by caregivers for their young children suggest the need for food-based interventions that incorporate strategies to improve the quality of streetfoods as a healthy complement to homeprepared foods for children.

\section{ACKNOWLEDGEMENT(S)}

This research and publication was supported by the Global Livestock Collaborative Research Support Program (GL-CRSP) funded in part by USAID, Grant \# PCE-G-0098-00036-00 and the Jim Ellis Mentorship Program for Graduate students. 


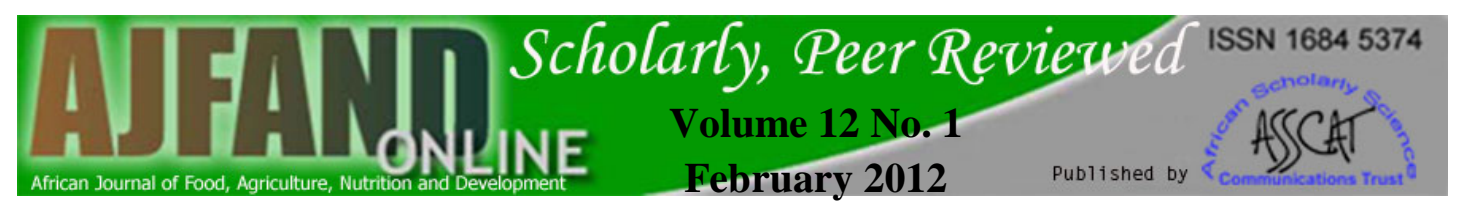

Table 1: Characteristics of caregivers and children from the Winneba and Techiman study areas

\begin{tabular}{|c|c|c|c|c|c|}
\hline \multirow{2}{*}{$\begin{array}{l}\text { CAREGIVER CHARACTERISTICS } \\
\text { Relationship to child }\end{array}$} & \multicolumn{4}{|c|}{ Study locale } & \multirow[b]{2}{*}{ P-value ${ }^{2}$} \\
\hline & \multicolumn{2}{|c|}{$\begin{array}{l}\text { Winneba } \\
(N=40)\end{array}$} & \multicolumn{2}{|c|}{$\begin{array}{c}\text { Techiman } \\
(\mathrm{N}=132)\end{array}$} & \\
\hline Biological mother & 77.5 & (31) & 97.0 & $(128)$ & $P<0.001$ \\
\hline Grandchild & 75.0 & (7) & 30.0 & (4) & \\
\hline Other ${ }^{4}$ & 5.0 & (2) & 0 & (0) & \\
\hline \multicolumn{6}{|l|}{ Occupation } \\
\hline Farming & 21.0 & (8) & 47.2 & $(57)$ & 0.001 \\
\hline Trading & 68.4 & (26) & 44.7 & (61) & \\
\hline Other ${ }^{3}$ & 10.5 & (4) & 8.1 & (11) & \\
\hline Unemployed & 5.0 & (2) & 3.6 & (3) & \\
\hline \multicolumn{6}{|l|}{ Marital status } \\
\hline Married & 80.0 & $(32)$ & 87.1 & $(115)$ & 0.306 \\
\hline Unmarried & 20.0 & (8) & 12.9 & (17) & \\
\hline Caregiver's age (yr) & 38.8 & \pm 1.8 & 32.0 & \pm 0.6 & 0.010 \\
\hline Parity (\#) & 4.9 & \pm 0.4 & 3.5 & \pm 0.2 & 0.002 \\
\hline Caregiver's schooling (yr) & 4.4 & \pm 0.7 & 5.8 & \pm 0.4 & 0.252 \\
\hline \multicolumn{6}{|l|}{ HOUSEHOLD CHARACTERISTICS } \\
\hline \multicolumn{6}{|l|}{ Household head sex } \\
\hline Male & 60.0 & $(24)$ & 81.8 & $(108)$ & 0.009 \\
\hline Female & 40.0 & (16) & 18.2 & (24) & \\
\hline Household size (\#) & 6.7 & \pm 0.3 & 7.2 & \pm 0.2 & 0.258 \\
\hline \multicolumn{6}{|l|}{ CHILD CHARACTERISTICS } \\
\hline \multicolumn{6}{|l|}{ Child Sex } \\
\hline Male & 45.0 & (18) & 51.5 & $(68)$ & 0.589 \\
\hline Female & 55.0 & $(22)$ & 48.5 & (64) & \\
\hline Age of child (mo) & 38.8 & \pm 9.4 & 42.7 & \pm 9.9 & 0.032 \\
\hline
\end{tabular}

${ }^{1}$ Values are shown as mean \pm SE or \% (n)

${ }^{2}$ Significance level associated with Chi-Square Statistic or Student's t-Test

${ }^{3}$ Other occupations included salaried worker $(n=3)$ and skilled artisan $(n=12)$

${ }^{4}$ Other relationships between child and caregiver includes stepchild(n=1) and aunt $(n=1)$ 
Table 2: Animal source food (ASF) intakes ${ }^{1}$ of children 2- to 5 -years old children in the Winneba and Techiman municipalities of Ghana

\begin{tabular}{|c|c|c|c|c|c|c|c|c|}
\hline Children's ASF intakes & & otal & $\begin{array}{r}\text { Win } \\
(\mathbf{n}=\end{array}$ & $\begin{array}{l}\text { Ineba } \\
=18)\end{array}$ & $\begin{array}{r}\text { Tec } \\
\text { (n }\end{array}$ & 2 & & P-value \\
\hline Total ASF (g) & 69.9 & $\pm 16.8^{3}$ & 54.2 & $\pm \quad 4.7$ & 80.4 & \pm & 28.0 & 0.455 \\
\hline $\mathrm{ASF}_{\text {from }} \mathrm{SF}^{2}$ (g) & 11.8 & $\pm \quad 5.4$ & 3.6 & $\pm \quad 0.9$ & 39.9 & \pm & 8.1 & 0.04 \\
\hline $\begin{array}{l}\text { SF contribution to ASF } \\
\text { intake (\%) }\end{array}$ & 15.5 & \pm 4.7 & 4.2 & $\pm \quad 1.0$ & 35.7 & \pm & 7.2 & $<0.01$ \\
\hline
\end{tabular}

Table 3: Mean percent contribution of ASF from street foods (SF) ${ }^{\mathbf{1}}$ to total energy and nutrient intakes of 2- to 5-years old children in the Winneba and Techiman communities of Ghana

\begin{tabular}{llll}
\hline Nutrient & Winneba (N=18) & Techiman (N=27) & P-value $^{2}$ \\
& & \\
\hline Energy & $0.9 \pm 0.6^{3}$ & $16.4 \pm 4.7$ & 0.003 \\
Protein & $7.2 \pm 6.2$ & $15.2 \pm 4.2$ & 0.283 \\
Calcium & $0.1 \pm 0.1$ & $15.4 \pm 4.8$ & 0.004 \\
Iron & $0.5 \pm 0.4$ & $30.0 \pm 13.0$ & 0.032 \\
Zinc & $0.7 \pm 0.5$ & $17.3 \pm 4.9$ & 0.002 \\
\hline${ }^{1}$ Analysis based on 2-day food assessment (12-hr weighed + 12-hr recall) on sub-sample of 45 children \\
${ }^{2}$ Significance associated with Student’s t-test \\
${ }^{3}$ Mean \pm SE
\end{tabular}

Table 4: Contribution of street foods (SF) to total energy and nutrient intakes of children aged 2- to 5-years old in the Winneba and Techiman municipalities ${ }^{1,2}$

\begin{tabular}{|c|c|c|c|c|}
\hline Nutrient & Total & Winneba $(\mathrm{N}=18)$ & Techiman $(\mathrm{N}=27)$ & P-Value $^{3}$ \\
\hline Energy & $35.3 \pm 2.3$ & $37.5 \pm 2.8$ & $33.8 \pm 3.4$ & 0.159 \\
\hline Protein & $28.3 \pm 2.1$ & $28.0 \pm 3.2$ & $28.5 \pm 2.8$ & 0.909 \\
\hline Calcium & $54.4 \pm 6.1$ & $62.8 \pm 10.7$ & $48.9 \pm 7.3$ & 0.301 \\
\hline Iron & $34.5 \pm 2.7$ & $39.4 \pm 4.6$ & $31.3 \pm 3.2$ & 0.144 \\
\hline Zinc & $29.7 \pm 2.3$ & $27.8 \pm 2.4$ & $30.9 \pm 3.5$ & 0.962 \\
\hline Vitamin A & $43.1 \pm 7.9$ & $38.2 \pm 11.7$ & $46.3 \pm 10.7$ & 0.621 \\
\hline Vitamin $\mathrm{B}_{12}$ & $20.3 \pm 5.2$ & $6.7 \pm 3.4$ & $31.9 \pm 9.5$ & 0.027 \\
\hline
\end{tabular}

${ }^{1}$ Analysis based on 2-day weighed food assessment on sub-sample of 45 children

${ }^{2}$ Mean \pm SE $(\%)$

${ }^{3}$ Significance associated with Student's t-test 


\section{REFERENCES}

1. Equity Policy Centre Utilizing street foods trade in development programme. Final report. Washington, DC: Equity Policy Centre, 1998.

2. Food and Agriculture Organization. School children, street foods and micronutrient deficiencies in Tanzania. Agriculture and Consumer Protection Department, 2007.

3. Maxwell D, Levin C, Amer-Klemesu M, Morris S, and C Ahiadeke Urban livelihoods and food and nutrition security in Greater Accra. Washington DC: International Food Policy Research Institute. Ghana Research Report 112, 2000.

4. FAO. Street foods: Report of an FAO expert Consultation Jogjakarta, FAO food and Nutrition paper no. 46. Rome. FAO Indonesia, 1988.

5. Kant AK and BI Graubard Eating out in America, 1987-2000 Trends and nutritional correlates. Prev. Med. 2004; 2:243-249.

6. Ruel M, Levin C, Amar-Klemesu M, Maxwell D and S Morris Goodcare practices can mitigate against the negative effects of poverty and low maternal schooling in children's nutritional status: Evidence from Accra. World.Dev. 1999;62:14-17.

7. Hussain MA Nutrition policy and the urban poor in developing countries. Food.Policy.1990; 15:186-192.

8. Lunven P Feeding the cities: a challenge for the future. Arch. Latinoam. Nutr.1994;44: 89-101.

9. Chauliac M, Monnier T and A Bendech Bamako school age children and their diets from street vendors. Santé 1994; 4: 413-423.

10. Neffati L, Ridha H, Kolsterep and PK Hilderbrand Street foods among children; a study in north Tunisia. Santé 2004; 1: 43-48.

11. Ruel MT, Haddad L, and JL Garrett Rapid urbanization and the challenges of obtaining food and nutrition security. In: Semba RD, Bloem MW, eds. Nutrition and Health in Developing Countries. Totowa, N.J.: Humana Press, 2001;22465-482.

12. Webb RE, and SA Hyatt Haitian street foods and their nutritional contribution to dietary intake. Ecol. Food.Nutr.1988; 21: 199-209. 
13. Tropical Health Organization (TNO), Food Technology Development Center (IPB), and Free University (VU). 1992. The role of street foods in household food consumption: A survey in Borgor, street food project working report no.6. Jakarta and The Hague: BPPT and DGIS. Cited in: Draper A. Street foods in developing countries.OMNI Project report.1996. http://www.mostproject.org/PDF/strtfoods2.pdf. (Accessed August 26, 210)

14. Taveras EM, Berkey CS, Rifas- Shiman SL, Ludwig DS, Rocket HR, Field A, Colditz GA, and WM Gillman Association of consumption of fried food away from home with body mass index and diet quality in older children and adolescent. Pediatr. 2005; 116: e518-e524.

15. Mensah P, Yeboah M, Owusu D, Darko K and A Ablordey Street food in Accra, Ghana: How safe are they? Bull. WHO.2002; 80: 546-554.

16. Murphy SP, Beaton GH and DH Calloway Estimated mineral intakes of toddlers: Predicted prevalence of inadequacy in village populations in Egypt, Kenya and Mexico. Am. J.Clin.Nutr.1994; 56: 565-572.

17. Murphy SP and HA Lindsay Nutritional importance of animal source foods. J.Nutr. 2003; 133: 3932S-3935S.

18. Neumann CG, Nimrod OB, Murphy S, Sigman M, Shannon W, Allen L, Guthrie D, Weiss RE and MW Demment Animal source foods improve dietary quality, micronutrient status growth and cognitive function in Kenyan School children: Background, study design and baseline findings. J. Nutr. 2003; 133: 3941S-3949S.

19. Lartey A, Colecraft E, Marquis GS, Sakyi-Dawson O, and B Ahunu Nutrition education with microcredit provided to caregivers of pre-school children: Effect on children's animal source food intake”. Global Livestock Collaborative Research Support Program (GL-CRSP). University of California, Davis. Research Brief 09-06-ENAM, 2009.

20. Eyeson KK, and EK Ankrah Composition of foods commonly used in Ghana. Accra. Food Research Institute, Council for Scientific and Industrial Research, 1975.

21. Kennedy G Food security in the context of urban Sub-Saharan Africa. Food Africa Internet Forum 31 March-11, 2003 April Internet Paper for Food Security. http://foodafrica.nri.org/security/securitypapers.html (Accessed August 26 2010)

22. Colecraft EK, Marquis GS, Bartolucci AA, Pulley L Owusu WB and MH A Maetz Longitudinal assessment of the diet and growth of malnourished children participating in nutrition rehabilitation centers in Accra. Public Health Nutr: 2003; 4: 487-494. 